\title{
Resource-Dependent Growth Models for Sierran Mixed-Conifer Saplings
}

\author{
Seth W. Bigelow ${ }^{*}, 1$, Malcolm P. North ${ }^{1,2}$ and William R. Horwath ${ }^{3}$ \\ ${ }^{1}$ Sierra Nevada Research Center, USDA Forest Service, Pacific Southwest Research Station, 1731 Research Park Drive, \\ Davis California, 95618, USA \\ ${ }^{2}$ Department of Plant Sciences, University of California-Davis, One Shields Avenue, Davis, California, 95616, USA \\ ${ }^{3}$ Department of Land, Air and Water Resources, University of California-Davis, One Shields Avenue, Davis, California \\ 95616, USA
}

\begin{abstract}
Thinning to reduce wildfire hazard is a common management practice in frequent-fire forests of the American west, but it is uncertain whether projects will help regenerate fire-resistant, shade-intolerant pines. We studied naturally established saplings of six conifer species in mixed-conifer forest in northern California, USA to determine how three environmental resources - light, soil moisture, and soil mineralizable nitrogen - affect stem radial growth. Likelihood principles were used to select among models of growth as a function of resources, age and size. There was support for models of growth as an exponential function of light for three species. Pinus jeffreyi growth was slow even at $40 \%$ full sun but increased sharply at higher light. Light-dependent growth of Pinus ponderosa and Calocedrus decurrens was contingent upon age: some young $(<20 \mathrm{y})$ saplings grew rapidly at $16 \%$ full sun, but older saplings required higher light for rapid growth. No relationship of light or other resources to growth was detected for three other species; instead, null models of size-dependent (Abies concolor, Pseudotsuga menziesii) or age-dependent (Pinus lambertiana) growth provided the most parsimonious explanations of growth patterns. These results suggest the latter species will not grow rapidly under more open canopies, but the scope of this inference is limited because few individuals of these more tolerant species were found in high-light environments. In contrast, large openings or patchy canopy are required for rapid growth of $P$. jeffreyi; smaller openings will increase growth of $P$. ponderosa, but increases may be modest unless saplings are young.
\end{abstract}

Keywords: Irradiance, hemispherical image analysis, light-dependent growth, carbon isotope, mixed-conifer, sapling, Michaelis-Menten, Sierra Nevada USA, soil moisture.

\section{INTRODUCTION}

In pre-settlement mixed-conifer forests of the Sierra Nevada and Southern Cascades, a high ( $\geq 50 \%)$ proportion of stems belonged to shade-intolerant tree species [1-5]. Forest tree species composition has changed dramatically in the past 150 years, and now smaller size classes are dominated by shade-tolerant species such as Abies concolor (white fir) and Calocedrus decurrens (incense-cedar) [6, 7]. Current management treatments and natural disturbances may present opportunities for slowing or reversing this trend by enhancing regeneration of shade-intolerant, fire-tolerant species such as Pinus ponderosa. These treatments and disturbances include fuels-reduction thinning [8], groupselection harvesting [9], and fires of varying intensity [10]. To understand how different disturbances may select for particular species, research is needed on species' growth responses to environmental resources - light, water, and nutrients - whose availability is determined in part by such disturbances.

Past studies that have used resource-based approaches to predict tree replacement dynamics in Sierran mixed-conifer

*Address correspondence to this author at the Sierra Nevada Research Center, USDA Forest Service, Pacific Southwest Research Station, 1731 Research Park Drive, Davis California 95618, USA; Tel: 530-759-1718; Fax: (530) 747-0241; E-mail: sbigelow@fs.fed.us forest have often used relatively simple representations of species' growth responses to light. Species were placed in two to four shade-tolerance classes, and assigned a generalized light-dependent growth curve [11, 12]. Lightdependent growth curves depict the tradeoff of rapid growth in low light and low growth in high light for shade-tolerant species, while the tradeoff for shade-intolerant species is the opposite [16]. Qualitative shade-tolerance classifications are well established for lower montane Sierran conifers: Abies concolor (Gord. and Glend.) Lindl. and Calocedrus decurrens (Torr.) Florin are classified as shade-tolerant, Pseudotsuga menziesii [(Mirb.) Franco] and Pinus lambertiana Dougl. as intermediate, Pinus ponderosa Laws as intolerant, and Pinus jeffreyi Grev. and Balf. as extremely intolerant [13-15]. Nevertheless, lack of empirically verified light-growth response curves for Sierra lower montane conifers limits accurate prediction of community-level responses to canopy-opening disturbance.

Modeling of Sierran tree growth response to water deficits has also been limited. Past studies have been done in the absence of field-measured, species-specific response curves; instead, growth responses to soil water deficits were inferred from species' distributions on the landscape [11, 12]. This procedure is likely to miss important features of conifer response to dry soil, because a species can be both highly drought tolerant and highly water-demanding [e.g., 17]. The qualitative ranking of Sierran lower-montane 
conifer species' demand for soil moisture is roughly opposite that of demand for light [14]: species are ranked from least(P. jeffreyi) to moderately- (P. lambertiana, $C$. decurrens, $P$. ponderosa) to most- demanding (P. menziesii, A. concolor). Ranking of drought tolerance can differ from ranking of demand for soil moisture for optimal growth; for example $P$. ponderosa, which is moderately demanding of soil moisture, is highly drought tolerant. Such reversals in ranking complicate inferences of growth response from species distributions across soil moisture gradients because species distributions are more likely to reflect tolerance than optimal growth [18]. Improved information on growth response to actual soil moisture would help with growth modeling.

Our study examined mixed-conifer sapling growth rates with respect to environmental resource availability, with the goal of providing tools to assist forest managers in influencing tree species composition. We had two main hypotheses. First, shade-tolerant and shade-intolerant species will show a reversal in growth ranking depending on light level: shade-tolerant species will show rapid growth in low light and slow growth in high light, and shade-intolerant species will show the reverse. Second, variation in soil moisture will explain more of the growth response of shade-tolerant, moisture-demanding species than of the shade-intolerant species. As an alternative hypothesis, we also tested the possibility that variation in growth is determined by soil nitrogen $(\mathrm{N})$ status. Even though soil $\mathrm{N}$ is not usually considered to be a strong determinant of plant performance in the Sierras, some studies [19, 20] have shown it can affect growth.

We carried out the study on wild-grown saplings to obtain results that would be directly applicable to field conditions. We located naturally established saplings of six conifer species growing across a precipitation gradient in Plumas National Forest in northern California. Each sapling was measured for stem growth and local availability of light and soil resources, and a series of growth models was fitted to the resulting data. One set of models expressed growth as a linear function of resource availability (light, soil moisture, or $\mathrm{N}$ ); a second set of models allowed for non-linear (saturating or exponential) responses to light. We also fitted versions of these linear and non-linear models that controlled for age or size effects. Age can be an important mediator of tree growth during the early years of life [21] and several of the species studied change growth rate as they develop. For example, Pinus lambertiana Dougl. grows slowly when young but accelerates later in development [22, 23], whereas $P$. ponderosa grows rapidly when young [24]. It can be difficult to distinguish between age and size effects on growth rates, however, and some researchers stress the role of size in the interpretation of sapling performance $[25,26]$. We tested for age and size effects on growth to control for these factors. The best model was selected based on principles of maximum likelihood.

\section{METHODS}

The study took place in Plumas National Forest, Plumas County, California, USA along a $55 \mathrm{~km}$ transect that ran from west to east across the main crest of the Sierra Nevada range (Fig. 1). Average annual precipitation along the transect varied from 800 - $2000 \mathrm{~mm}$ [27]; median of average monthly growing season (April-September) precipitation for the four years up to and including the year of the study was 7 $\mathrm{mm}$ [28]. Evaporation for one year at a forested site $\sim 150 \mathrm{~km}$ distant at $1300 \mathrm{~m}$ elevation was $728 \mathrm{~mm}$ [29]. Forest types were mixed-conifer and true fir at altitudes from 1200 to $1900 \mathrm{~m}$. Samples were clustered in four areas along the transect; soil series in these areas were Chaix (a Dystroxerept), Skalan, and Holland (both Haploxeralfs). Chaix and Holland soils are formed from granitic parent material, and Skalan soils are formed from metamorphosed sedimentary rocks. Ultramafic soils were excluded from our sampling because only $C$. decurrens and $P$. jeffreyi occur in abundance on those soils. Along the transect we searched for saplings (defined operationally as $0.5-2 \mathrm{~m}$ in height) in four areas, finding 37 to 40 individuals each of $A$. concolor, $P$. menziesii, $C$. decurrens, $P$. lambertiana, $P$. ponderosa, and $P$. jeffreyi. Species were intermingled within stands, except for P. jeffreyi which occurred at higher elevations (Table 1).

Physiographic (slope, aspect, elevation) and soil attributes were measured for each sapling. Aspect was converted to orientation along a north-east to south-west axis using the formula $[(1-$ cosine (aspect-45 $)) / 2]$ [30], where values range between 0 for a north-east facing site and 1 for a south-west facing site. The thickness of the soil organic horizon $\left(\mathrm{O}_{\mathrm{e}}\right.$ and $\left.\mathrm{O}_{\mathrm{a}}\right)$ was measured on opposite sides of each sapling at $0.5 \mathrm{~m}$ from the stem, and the mean depth to restrictive layer was assessed by inserting a tile probe (a slender metal rod with a handle and pointed tip) at the same locations. A composite soil sample was collected in June and in late September 2003, i.e., at the beginning and the end of the growing season $(2$ cores from $0-0.2 \mathrm{~m}$ depth at $0.5 \mathrm{~m}$ from the base of each sapling). These samples were immediately placed in tin canisters and sealed with Parafilm. Wet weights were obtained the same day and dry weights were obtained after drying for $24 \mathrm{hrs}$ at $100^{\circ} \mathrm{C}$. The assumptions underlying this water availability assay are that soils are nearly fully recharged early in the season after snow-melt, and that little precipitation occurs during the growing season.

Soil samples collected in September 2003 were analyzed for mineralizable $\mathrm{N}$ with an anaerobic incubation [19]. Thirty $\mathrm{mL}$ of deionized water were added to a tube containing $10 \mathrm{~g}$ of soil and shaken, nitrogen gas was bubbled through the slurry for $1 \mathrm{~min}$ to remove oxygen, then the tube was sealed and incubated at $40^{\circ} \mathrm{C}$. The sample was removed after $7 \mathrm{~d}$ and $10 \mathrm{~mL}$ of $4 \mathrm{M} \mathrm{KCl}$ were added, then the tube was shaken by hand and mechanically agitated for $30 \mathrm{~min}$. Sixty uL of the supernatant that subsequently formed was filtered and combined with two reagents in a cuvette to produce the salicylate analog of indophenol blue [31]. The solution was shaken and rested for 1-2 hr, then absorbance at $650 \mathrm{~nm}$ was read and regressed against standards to determine ammonium concentration. For $\mathrm{pH}, 15 \mathrm{~g}$ of soil were added to $15 \mathrm{~mL}$ deionized water, shaken, rested for 12 hours, then 10 $\mathrm{mL}$ of $4 \mathrm{M} \mathrm{KCl}$ solution were added. After $30 \mathrm{~min}$ of repose the supernatant was measured with a $\mathrm{pH}$ meter (Denver Instruments, Denver Colorado).

A colour photograph of the canopy above each sapling was taken with a leveled, tripod-mounted (1.3 m height) Nikon Coolpix 4500 digital camera equipped with a fisheye lens. Photos were taken from 4 - 17 June, 2003. Canopy openness (the proportion of the hemisphere over each 


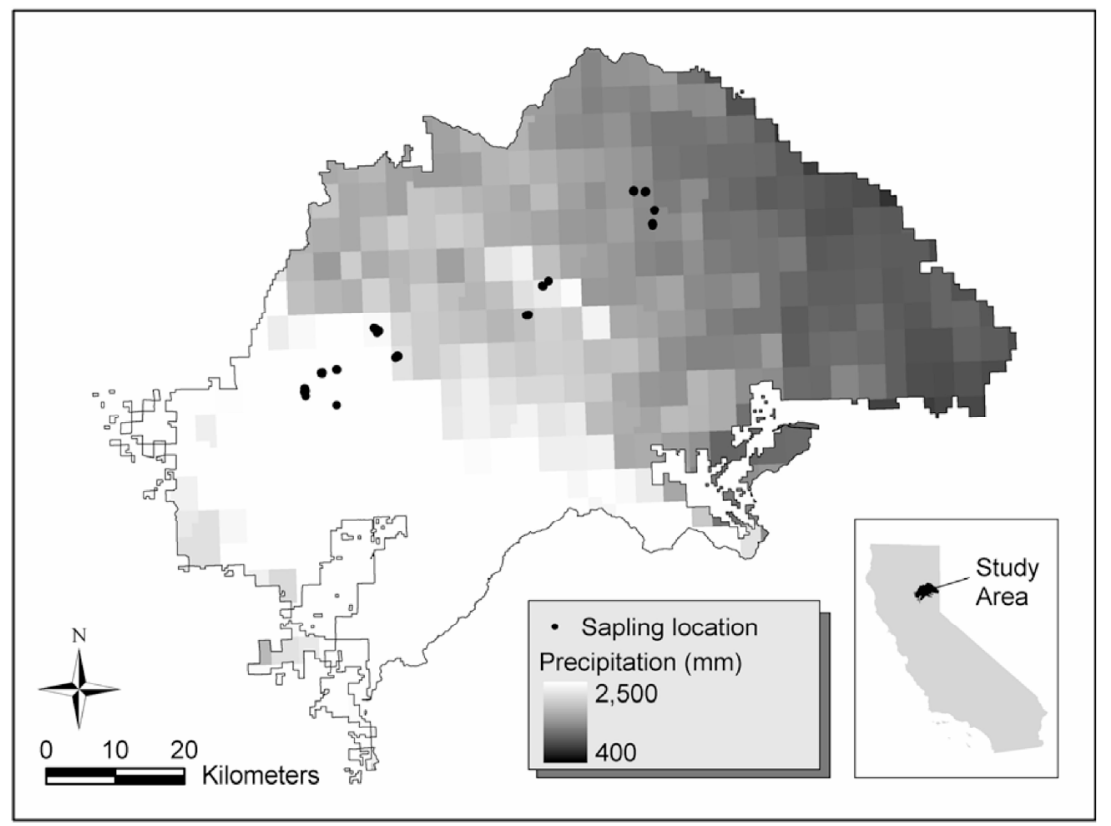

Fig. (1). Locations in the Plumas National Forest where saplings were collected. Shading indicates average annual precipitation (Spatial Climate Analysis Service 2006).

Table 1. Mean and Standard Deviation of Physiographic, Soil, Canopy, and Sapling Characteristics, Measured for Saplings of Six Mid-Elevation Conifer Species of the Northern Sierra Nevada-Southern Cascades Ranges. Means in the Same Row with Different Superscripts are Significantly Different $(p<0.05$, MANOVA with Post-Hoc Tukey's Test)

\begin{tabular}{|c|c|c|c|c|c|c|c|}
\hline Attribute & Units & A. concolor & P. menziesii & C. decurrens & P. lambertiana & $P$. ponderosa & P. jeffreyi \\
\hline NE-SW axis ${ }^{1}$ & & $0.60^{\mathrm{a}}(0.34)$ & $0.60^{\mathrm{a}}(0.29)$ & $0.62^{\mathrm{a}}(0.29)$ & $0.50^{\mathrm{a}}(0.31)$ & $0.64^{\mathrm{ab}}(0.32)$ & $0.81^{\mathrm{b}}(0.20)$ \\
\hline Slope & $\%$ & $29^{\mathrm{a}}(15)$ & $25^{\mathrm{a}}(15)$ & $27^{\mathrm{a}}(11)$ & $33^{\mathrm{a}}(14)$ & $28^{\mathrm{a}}(16)$ & $16^{\mathrm{b}}(10)$ \\
\hline Soil depth & $\mathrm{cm}$ & $50(32)$ & $47(28)$ & $43(24)$ & $41(25)$ & $45(31)$ & $46(32)$ \\
\hline Elevation & $\mathrm{km}$ & $1.34^{\mathrm{ab}}(0.09)$ & $1.34^{\mathrm{a}}(0.05)$ & $1.35^{\mathrm{a}}(0.08)$ & $1.42^{\mathrm{bc}}(0.14)$ & $1.36^{\mathrm{ab}}(0.09)$ & $1.74^{\mathrm{d}}(0.10)$ \\
\hline O horizon depth & $\mathrm{cm}$ & $4.8(3.4)$ & $4.5(1.9)$ & $4.6(2.4)$ & $4.5(2.5)$ & $4.5(3.6)$ & $3.1(2.7)$ \\
\hline Canopy openness ${ }^{2}$ & $\%$ & $15.3^{\mathrm{a}}(5.2)$ & $14.1^{\mathrm{a}}(4.4)$ & $14.3^{\mathrm{a}}(5.8)$ & $16.5^{\mathrm{a}}(4.6)$ & $18.5^{\mathrm{a}}(8.0)$ & $30.5^{\mathrm{b}}(14.3)$ \\
\hline Irradiance $\mathrm{e}^{3} \mathrm{~mol} \mathrm{~m}^{-2} \mathrm{~d}^{-1}$ & & $16.0^{\mathrm{a}}(8.0)$ & $13.6^{\mathrm{a}}(6.8)$ & $15.3^{\mathrm{a}}(7.1)$ & $17.9^{\mathrm{a}}(5.8)$ & $19.4^{\mathrm{a}}(10.2)$ & $29.6^{\mathrm{b}}(14.4)$ \\
\hline Soil mass wetness $(w)^{4}$ & $\mathrm{~g} / \mathrm{g}$ & $0.201(0.227)$ & $0.176(0.153)$ & $0.181(0.104)$ & $0.153(0.057)$ & $0.139(0.097)$ & $0.151(0.085)$ \\
\hline Wetness change $(\Delta w)^{5}$ & $\mathrm{~g} / \mathrm{g}$ & $0.088(0.221)$ & $0.100(0.145)$ & $0.094(0.081)$ & $0.069(0.042)$ & $0.070(0.079)$ & $0.075(0.084)$ \\
\hline$\delta^{13} \mathrm{C}$ of stem wood ${ }^{6}$ & $\%$ & $-26.6^{\mathrm{bc}}(1.0)$ & $-27.2^{\mathrm{c}}(1.0)$ & $-26.0^{\mathrm{b}}(1.2)$ & $-26.2^{\mathrm{b}}(1.2)$ & $-26.1^{\mathrm{b}}(1.1)$ & $-24.8^{\mathrm{a}}(1.2)$ \\
\hline Mineralizable $\mathrm{N}^{7}$ & $\mathrm{mg} / \mathrm{g}$ & $0.307(0.207)$ & $0.301(0.243)$ & $0.312(0.182)$ & $0.272(0.148)$ & $0.301(0.355)$ & $0.393(0.306)$ \\
\hline Soil $\mathrm{pH}^{8}$ & & $5.29^{\mathrm{ab}}(0.53)$ & $5.18^{\mathrm{ab}}(0.51)$ & $5.32^{\mathrm{b}}(0.54)$ & $5.18^{\mathrm{ab}}(0.60)$ & $5.22^{\mathrm{ab}}(0.68)$ & $4.92^{\mathrm{a}}(0.45)$ \\
\hline Age & $\mathrm{yr}$ & $34(17)$ & $28(12)$ & $38(18)$ & $39(20)$ & $36(22)$ & $33(17)$ \\
\hline Height & $\mathrm{m}$ & $1.22(0.35)^{\mathrm{ab}}$ & $1.09^{\mathrm{ab}}(0.35)$ & $1.10^{\mathrm{ab}}(0.35)$ & $1.03^{\mathrm{a}}(0.33)$ & $1.23^{\mathrm{ab}}(0.42)$ & $1.26^{\mathrm{b}}(0.34)$ \\
\hline Stem diameter & $\mathrm{mm}$ & $26.2(9.0)^{\mathrm{ab}}$ & $22.3^{\mathrm{a}}(9.6)$ & $27.2^{\mathrm{ab}}(13.7)$ & $26.2^{\mathrm{ab}}(14.3)$ & $32.0^{\mathrm{b}}(14.5)$ & $32.0^{\mathrm{b}}(13.8)$ \\
\hline
\end{tabular}

${ }^{1} 0$ is north-east facing, 1 is southwest facing (see methods section).

${ }^{2}$ Proportion of sky hemisphere not obscured by vegetation or topography.

${ }^{3}$ Understory irradiance, average daily growing season photosynthetic photon flux density estimated from canopy photography.

${ }^{4}$ Soil mass wetness measured at onset of growing season, i.e, late May/early June $(w)$.

${ }^{5}$ Early-season minus late-season soil mass wetness $(\Delta w)$

${ }^{6}$ Stable carbon isotope ratio of stem wood grown from $1999-2003\left(\delta^{13} \mathrm{C}\right)$

${ }^{7}$ Mineralizable N $(\min -N)$

${ }^{8} \mathrm{Soil} \mathrm{pH}$ in $\mathrm{KCl}\left(\mathrm{pH} \mathrm{KCl}_{2}\right)$

sapling consisting of open sky) and mean daily growing season irradiance in the understory $\left(I ; \mathrm{mol} \mathrm{m}^{-2} \mathrm{~d}^{-1}\right.$ of quanta) were estimated from the photographs using the image analysis program GLA 2.0 [32]. Above-canopy irradiance was estimated at $62 \mathrm{~mol} \mathrm{~m}^{-2} \mathrm{~d}^{-1}$ based on the assumptions of a spectral fraction of 0.45 [33], clear-sky atmospheric transmittance of 0.8 , a cloudiness index of 0.8 , and a photosynthetically active radiation beam fraction of 0.9 [34]. The growing season was assumed to extend from 1 April 30 September [29, 35]. 
Saplings were harvested in early October, 2003. Stem sections at $100 \mathrm{~mm}$ above the soil surface were sanded then viewed with a computer-interfaced microscope to determine the width of growth rings from the 3 years prior to harvest. Rings were measured along three axes spaced 120 degrees apart to minimize anisotropic growth influence. Annual growth was expressed as the average increase in stem radius over the three years comprising the $2001-2003$ growing seasons. Sapling age was also determined. Because trees were aged at $100 \mathrm{~mm}$ stem height, actual age could be $\geq 1 \mathrm{yr}$ older than reported age.

We used the stable carbon isotope ratio, $\delta^{13} \mathrm{C}$, of stem wood as a supplemental index of environmental water availability. An annulus of wood containing the 5 most recent growth rings (i.e., representing the years 1999-2003) was purified to alpha-cellulose [36] and analyzed for ${ }^{12} \mathrm{C}$ and ${ }^{13} \mathrm{C}$ with a mass spectrometer. When growth is limited by water, higher $\delta^{13} \mathrm{C}$ is expected because decreased stomatal conductance leads to less discrimination against the heavier ${ }^{13} \mathrm{C}$ carbon isotope. Warren et al. [37] found that $\delta^{13} \mathrm{C}$ is a useful indicator of conifer drought stress in seasonally dry climates where potential annual evaporation $\left(\mathrm{ET}_{\mathrm{p}}\right)$ exceeds precipitation, and when other sources of variability such as elevation or atmospheric mixing can be controlled. Our study area is seasonally dry, and although precipitation exceeds $\mathrm{ET}_{\mathrm{p}}$ up to half of the precipitation falls as snow which runs off rapidly in the spring and becomes unavailable for plant uptake [38].

\section{Models and Statistical Analysis}

A multiple analysis of variance (MANOVA) was used to test whether the means of the independent variables that described soils, physiography, and sapling attributes differed among the six tree species. Post-hoc multiple comparisons among means were made with Tukey's test (General Linear Model procedure)[39].

We identified the resources most strongly associated with sapling radial growth by fitting data on irradiance, earlyseason soil moisture, and $\mathrm{N}$ to a series of models. Earlyseason soil moisture was used in preference to the difference between early- and late-season soil moisture because these measures were highly correlated and the early-season metric was simpler. The basic model was $G=a+b X$, where $G$ is stem radius growth rate in $\mathrm{mm} / \mathrm{y}, X$ is availability of a resource, and $a$ and $b$ are estimated parameters. A second series of models expressed the potential influence of sapling diameter or age on growth rate. The form of these models was $G=(a+b X) \cdot Y^{c}$, where $Y$ is diameter or age and $c$ is a scaling parameter that is estimated from the data $[21,40]$.

Sapling growth response to light is often modeled with the Michaelis-Menten formula, a first-degree inverse polynomial with the form $\mathrm{G}=a I_{(}(a / b+I)$ where $I$ is understory irradiance [16]. Notable properties of this model are that growth rate is zero when irradiance is zero and that growth tapers off to an asymptote (expressed by the $a$ parameter) at high irradiance. We fitted growth and light data to the Michaelis-Menten equation and to a form of the exponential function for growth, $G=e^{a-b I}$, that provides parameter estimates that have minimal variance and bias and are normally distributed [41]. Both models were modified to include effects of age or light. The modified exponential function took the form $G=a e^{b I} Y^{c}$ [41], and the modified Michaelis-Menten took the form $G=\left(a I /\left(a / Y^{b}+I\right)\right) \cdot Y^{c}$, where the $Y^{b}$ parameter allows the shape of the growth curve at low light to change according to the magnitude of the diameter or age covariate.

Parameters were fitted to the data with an optimization routine that selected values that maximized the likelihood of observing the data. We used an implementation of the Metropolis algorithm programmed in the $\mathrm{R}$ statistical language [42] by Lora Murphy and Charles Canham (Cary Institute for Ecosystem Studies). Akaike's Information Criterion corrected for small sample size $\left(\mathrm{AIC}_{c}\right)$ was used to select the most informative, parsimonious model for the data. The model with lowest $\mathrm{AIC}_{c}$ (i.e., $\mathrm{AIC}_{\text {min }}$ ) was selected as the best model, and the difference between $\mathrm{AIC}_{\text {min }}$ and $\mathrm{AIC}_{c}$ of other candidate models (i.e., $\Delta_{i}=\mathrm{AIC}_{i}-\mathrm{AIC}_{\text {min }}$ ) was used to assess support for candidate models. Models with $\Delta_{i}<2$ are considered to have substantial support, and models with $\Delta_{i}>10$ have essentially no support [43]. The usefulness of candidate models of resource-dependent growth was also judged by comparing their $\mathrm{AIC}_{c}$ to that of several null models that lacked a term for resource dependence. One such model expressed growth as a simple mean, and the others contained a constant multiplied by an estimated age- or sizescaling term, e.g., $G=b Y^{c}$. Parameter support limits reported are the range of parameters for which the log-likelihood is within 2 units of the maximum likelihood value [44].

\section{RESULTS}

\section{Species Distributions Among Microsites}

There was little microsite differentiation among species (Table 1). Soil depth $(p=0.79)$ and organic horizon depth $(p$ $=0.08$ ) did not differ significantly among species, and even though axis $(p=0.0003)$, slope $(p=0.0001)$ and canopy openness $(p=0.0001)$ were significantly different among species, post-hoc multiple comparisons indicated the finding of significance was due solely to $P$. jeffreyi, which occurred on open sites with southwesterly exposure (NE-SW axis close to 1) and gentle slopes.

Neither mineralizable nitrogen $(p=0.37)$ nor earlyseason soil moisture $(p=0.37)$ differed among species. Soil $\mathrm{pH}$ did differ significantly among species $(p=0.028) ; P$. jeffreyi occurred on more acidic soils than $A$. concolor or $C$. decurrens (Tukey's test). The carbon isotope ratio differed among species $(p=0.0001)$; Pinus jeffreyi had the highest (i.e., least negative) stem wood $\delta^{13} \mathrm{C}$ signature, $P$. menziesii the lowest, and other species had intermediate values. Mean age of the individuals of the six species ranged from 28 to 39 years old.

\section{Species Responses to Resource Availability}

The matrix of linear correlations of growth with intrinsic and environmental factors showed only one strong correlation (for light and $P$. jeffreyi growth), but some of the weaker correlations were consistent across most species (Table 2). The correlation between growth and $\delta^{13} \mathrm{C}$ was $r \geq$ 0.30 for 5 of 6 species (P. lambertiana was the exception), but a positive correlation is the opposite of expected if water stress were limiting growth. There was a positive correlation between growth and elevation $(r \geq 0.33)$, and for growth and NE-SW axis $(r \geq 0.29)$, for the same five species. There was 
Table 2. Correlation Coefficients (r) Between Average Stem Radial Growth Rate from 2001 to 2003 and Intrinsic and External Factors Impinging on Saplings of Six Mixed-Conifer Species. Highest Absolute $r$ of Each Species is in Bold. Abbreviations are Explained in Table 1

\begin{tabular}{|c|c|c|c|c|c|c|}
\hline Factors & Abies concolor & Pseudotsuga menziesii & Calocedrus decurrens & Pinus lambertiana & Pinus ponderosa & Pinus jeffreyi \\
\hline$I_{u}$ & -0.03 & 0.08 & 0.26 & -0.05 & 0.37 & 0.72 \\
\hline$w$ & 0.01 & 0.55 & 0.11 & 0.20 & 0.34 & -0.43 \\
\hline$\Delta w$ & -0.00 & 0.55 & 0.13 & 0.16 & 0.40 & -0.50 \\
\hline $\min -N$ & 0.07 & -0.23 & -0.08 & 0.15 & 0.04 & 0.08 \\
\hline$p H_{K C l}$ & 0.03 & -0.13 & -0.29 & -0.14 & 0.21 & 0.29 \\
\hline$\delta^{13} C$ & 0.43 & 0.31 & 0.33 & -0.06 & 0.30 & 0.50 \\
\hline Age & -0.32 & -0.33 & -0.39 & -0.37 & -0.51 & -0.35 \\
\hline$H t$ & 0.19 & 0.29 & 0.19 & 0.29 & 0.05 & 0.11 \\
\hline$N E-S W$ axis & 0.29 & 0.32 & 0.44 & 0.23 & 0.44 & 0.33 \\
\hline Elevation & 0.33 & 0.43 & 0.54 & 0.10 & 0.50 & 0.51 \\
\hline
\end{tabular}

a negative correlation $(r<-0.32)$ with age for all species, indicating slower growth of older individuals. Correlations among growth and other factors were either very weak $(r<$ $0.25)$ or variable across species.

For three of the six species, resource-dependent models were ineffective at predicting growth. Null models lacking resource-dependent terms produced lowest $\mathrm{AIC}_{c}$ for these species (Table 3). The A. concolor and P. menziesii data were best explained by the null model that scaled growth by stem diameter. The positive sign of the size-scaling parameters ( $A$. concolor, $c=0.61 ; P$. menziesii, $c=0.62$ ) indicates that large-diameter individuals grew faster than small ones (Table 4). Only a small portion of the variation in the data relative to the mean was explained by the model $\left(R^{2}\right.$ $=0.15-0.16$ ). (One outlying observation for $P$. menziesii with excessive influence on the likelihood was removed from the data set; stem radial growth $1.7 \mathrm{~mm} / \mathrm{y}$, soil moisture $1.00 \mathrm{~g} / \mathrm{g})$. The Pinus lambertiana data were best explained by the null model that scaled growth by age; the negative

Table 3. Corrected Akaike Information Critierion (AIC ( $_{c}$ ) for Models of Stem Radial Growth with Respect to the Resources Understory Irradiance (I), Early-Season Soil Moisture $(w)$, or Mineralizable $N(N)$. Bold Font Denotes Best Model $\left(\mathrm{AIC}_{\min }\right)$

\begin{tabular}{|c|c|c|c|c|c|c|}
\hline$a$ & 9.6 & 14.9 & 45.1 & 29.0 & 111.1 & 68.4 \\
\hline$b \cdot \operatorname{diam}^{c}$ & 5.9 & 10.4 & 44.1 & 28.1 & 109.7 & 58.7 \\
\hline$a+b I$ & 11.9 & 16.7 & 40.9 & 31.2 & 107.8 & 26.6 \\
\hline$a+b N$ & 11.7 & 15 & 47.0 & 30.4 & 113.4 & 70.0 \\
\hline$(a+b I) \cdot a g e^{c}$ & 16.2 & 18.7 & 27.6 & 23.0 & 72 & 33.0 \\
\hline$(a+b w) \cdot a g e^{c}$ & 15.9 & 14.9 & 30.8 & 20.3 & 88.8 & 51.8 \\
\hline$(a+b N) \cdot a g e^{c}$ & 15.4 & 13.6 & 30.2 & 22.1 & 87.1 & 50.5 \\
\hline$a I /(a / b+I)$ & 11.1 & 17.2 & 44.1 & 31.1 & 107.8 & 33.5 \\
\hline$a I /\left(a / a g e^{b}+I\right) \cdot a g e^{c}$ & 11.6 & 14.7 & 24.4 & 22.9 & 73.1 & 34.4 \\
\hline $\operatorname{aI} /\left(\operatorname{adiam}^{b}+I\right) \cdot \operatorname{diam}^{c}$ & 6.1 & 13.2 & 45.3 & 30.5 & 108.5 & 32.7 \\
\hline $\exp (a-b I)$ & 12.0 & 16.7 & 45.1 & 31.3 & 104.1 & 20.0 \\
\hline$a(\exp (b I)) \cdot a g e^{c}$ & 12.3 & 14.6 & 23.4 & 22.6 & 64.4 & 22.5 \\
\hline$a(\exp (b I)) \cdot \operatorname{diam}^{c}$ & 8.4 & 12.8 & 53.1 & 30.5 & 111 & 5.2 \\
\hline
\end{tabular}


Table 4. Equations and Parameter Values for Best Models of Sapling Radial Growth (mm/y) with Respect to Environmental Resources. Also Reported are Estimated Variance $\left(S^{2}\right)$, Number of Parameters for Best Model $\left(K_{i}\right.$; Variance is Counted as a Parameter), Number of Observations (n), and the Adjusted Correlation Coefficient $\left(R^{2}\right)$. Footnotes Provide Support Intervals for Parameter Estimates

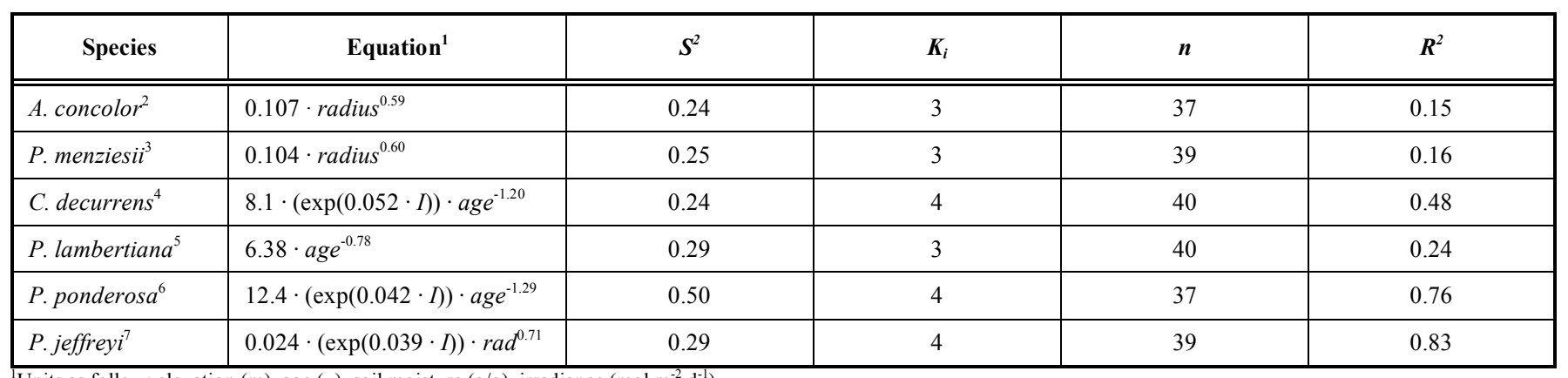

${ }^{1}$ Units as follow: elevation $(\mathrm{m})$, age $(\mathrm{y})$, soil moisture $(\mathrm{g} / \mathrm{g})$, irradiance $\left(\mathrm{mol} \mathrm{m}^{-2} \mathrm{~d}^{-1}\right)$.

${ }^{2}$ Support (in order in which it appears in the equation): $b(0.090-0.125), c(0.52-0.65)$.

${ }^{3} b(0.085-0.125), c(0.52-0.67)$.

${ }^{4} a(6.3-9.5), b(0.039-0.059), c(-1.28--1.14)$.

${ }^{5} b(5.14-7.68), c(-0.85--0.73)$.

${ }^{6} a(10.6-14.3), b(0.038-0.046), c(-1.36--1.23)$

${ }^{7} a(0.022-0.026), b(0.037-0.041), c(0.68-0.75)$

sign of the age-scaling parameter $(c=-1.29)$ indicated old saplings grew more slowly than young ones.

The $C$. decurrens' data were best explained by models that incorporated light and that scaled growth by age. The negative sign of the age-scaling parameter $(c=-1.2)$ denoted slower radial growth of older saplings. The best model had $\mathrm{AIC}_{c}=\mathrm{AIC}_{\text {min }}$ of 23.4, compared to an $\mathrm{AIC}_{c}$ of 28.9 for the age-scaled null model, and to an $\mathrm{AIC}_{\mathrm{c}}$ of 45.1 for the mean null model. The relative magnitude of the increases in $\mathrm{AIC}_{\mathrm{c}}$ from best model to age-scaled null model to mean null model indicated that the light-dependent component of the model explained a smaller portion of the variation in the data than the age-scaling component. Still, the AIC difference of $\Delta_{i}=5.5$ for the age-scaled null model indicated considerable support for the best model. The exact ratio of the likelihoods of these or any two models $\left(L_{\mathrm{i}} / L_{\mathrm{j}}\right.$, also known as the evidence ratio) is equivalent to $\exp \left(\left(A I C_{j}-A I C_{i}\right) / 2\right)$ [43]. Consequently, the evidence ratio of the two models was 15.6 $=\exp ((28.9-23.4) / 2)$, i.e., the age-scaled light-dependent model was 15.6 times more likely than the age-scaled null model given the data. There was negligible difference between the exponential and Michaelis-Menten forms of the age-scaled light-dependent model $\left(\mathrm{AIC}_{\mathrm{c}}=23.4\right.$ and 24.4, respectively; Table 3), but the estimate of the $a$ (i.e., asymptote) parameter of the Michaelis-Menten model was poorly constrained: its support interval varied from $(<0$ to $>300$ ). The large uncertainty about the $a$ parameter emphasized the superiority of the age-scaled exponential model.

The $P$. ponderosa data, like those of $C$. decurrens, were best explained by the age-scaled model of growth as an exponential function of light; older saplings grew more slowly. Unlike $C$. decurrens, the age-scaling and lightdependent components of the best model accounted for approximately equal portions of the variation in the data; the magnitude of the increase in $\mathrm{AIC}_{\mathrm{c}}$ from best model to growth-scaled null model (64.4 to 90.4) was comparable to the increase from aged-scaled null to mean null model ( 90.4 to 111.1). The age-scaled Michaelis-Menten $\left(\Delta_{i}=8.7\right)$ and linear $\left(\Delta_{i}=7.6\right)$ models both had considerably less support than the best model but were much better than the null models. The $P$. ponderosa data were much more variable than those of the other species, as shown by the large amount of scatter in the plot of growth against irradiance (Fig. 2), and the high estimated variance (Table $4 ; S^{2}=0.50$ ).

All light-dependent growth models of $P$. jeffreyi received strong support from the data (Table 3). One observation with large influence on likelihood estimates was removed from the dataset (radial growth $=3.3 \mathrm{~mm} / \mathrm{y}$, irradiance $=39 \mathrm{~mol}$ $\left.\mathrm{m}^{-2} \mathrm{~d}^{-1}\right)$. The size-scaled exponential model of lightdependent growth was the best model $\left(\mathrm{AIC}_{\min }=5.2\right)$. The positive sign of the size-scaling parameter $(c=0.71)$ indicated that larger individuals grew more rapidly than smaller individuals under similar irradiance. The $\mathrm{AIC}_{c}$ increase from $\mathrm{AIC}_{\text {min }}$ to the $\mathrm{AIC}_{c}$ of the size-scaled null model (5.2 to 58.7) was far larger than the $\mathrm{AIC}_{c}$ increase from the size-scaled null to the mean null model (58.7 to 68.4), indicating that the influence of light on growth was much larger than the size-scaling effect. The second-best model, a size-scaled linear model of light-dependent growth, had $\Delta_{i}=11.8$, and therefore was highly unlikely to be competitive with the best model; the evidence ratio was 365 $=\exp (11.8 / 2)$.

\section{DISCUSSION}

\section{Light Limitation to Sapling Growth}

The lack of relationship between growth and light for three of the six species (A. concolor, P. menziesii, and $P$. lambertiana) prevented evaluation of the main hypothesis about light-dependent growth curves of shade tolerant versus intolerant species. We attribute the non-detection of lightdependent growth to a sparse sample of trees under very low-light conditions, and to imprecision in hemispherical image analysis at low light. Growth rate of shade-intolerant species often approaches an asymptote at comparatively low light, hence the usefulness of models such as the MichaelisMenten [16]. Estimation of parameters for such models, though, depends on sampling a sufficient number of individuals at light levels well below those at which growth nears the asymptote. For the present study, that point would 


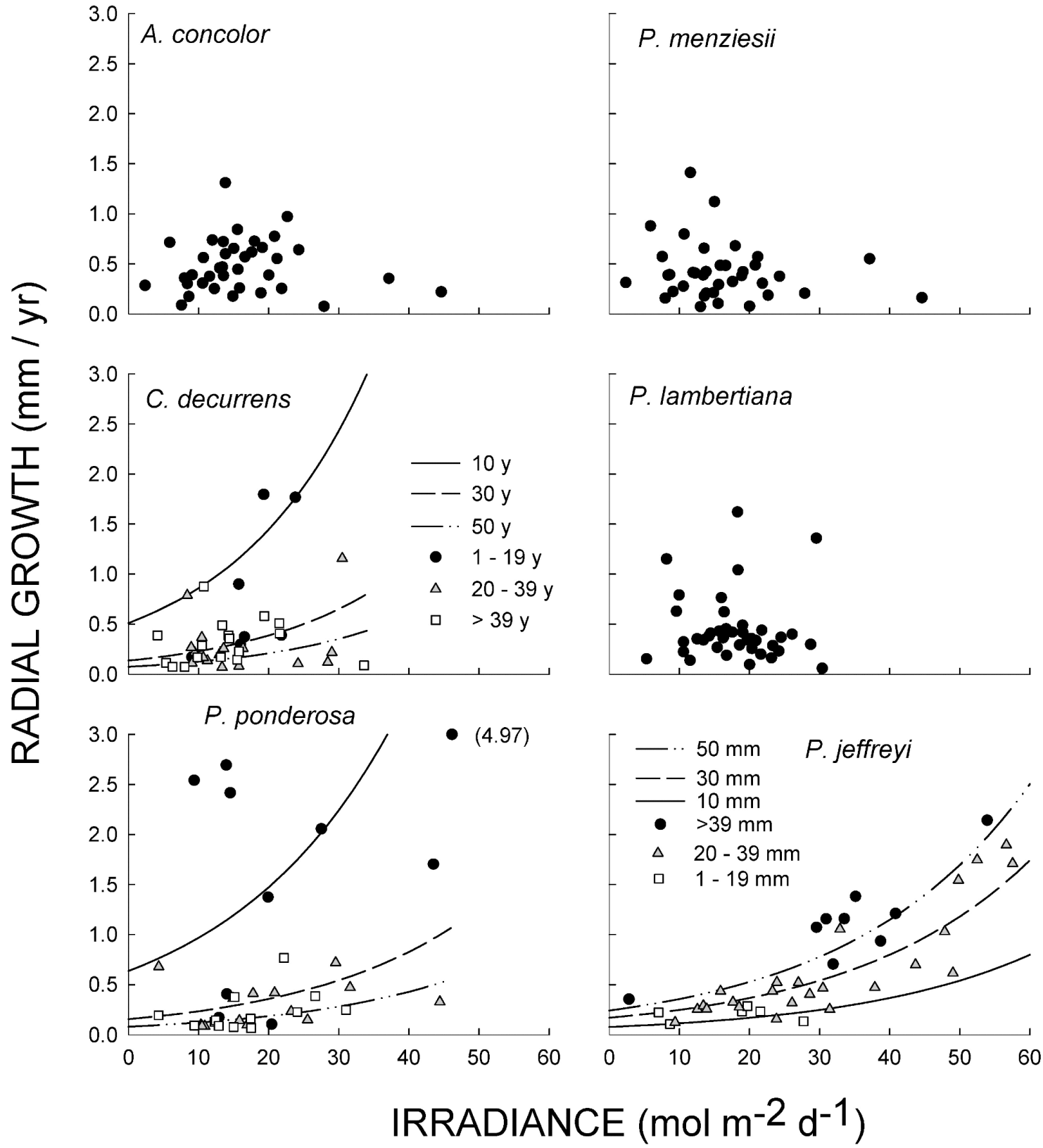

Fig. (2). Average annual stem radius growth ( $\mathrm{mm} / \mathrm{yr})$ plotted against mean daily growing-season irradiance $\left(\mathrm{mol} \mathrm{m}^{-2} \mathrm{~d}^{-1}\right)$ for saplings of six conifer species. Observed data (symbols) and predicted values (lines). For species that had a relationship with growth and light, growth is predicted at 10,30, and $50 \mathrm{y}$ for species influenced by age (C. decurrens, and $P$. ponderosa), and at 10, 30, and $50 \mathrm{~mm}$ stem diameter for $P$. jeffreyi. No relationship between growth and environmental resources was detected for A. concolor, P. menziesii, or $P$. lambertiana.

certainly be less than $10 \mathrm{~mol} \mathrm{~m}^{-2} \mathrm{~d}^{-1}$ of light (Fig. 2), and it appears that our sample is sparse there. The problem is exacerbated by the technical issue that irradiance estimates from hemispherical image analysis are least accurate in low light because they do not incorporate penumbral effects or light scattering [45]. The relatively small number of saplings at high light was less likely to have been an issue, at least for A. concolor and P. menziesii, because of their shadetolerance.

Light-dependent growth rates in $P$. jeffreyi, $P$. ponderosa, and $C$. decurrens were best modeled with a modified exponential increase in growth as a function of light availability. The response of $P$. ponderosa and $C$. decurrens to light was complicated by age-dependence. Young $(<20 \mathrm{y}$ old) saplings grew much more rapidly than older ones, and there was high variation in the growth rates of these young saplings which contributed to uncertainty in model selection. For C. decurrens, the age-modified exponential and Michaelis-Menten models had almost equal support from the data (Table 3). For $P$. ponderosa, though, the age-modified exponential equation was considerably better than the nextbest models (the age-modified linear and Michaelis-Menten models, with $\Delta_{i}=7.6$ and $\Delta_{i}=8.7$, respectively). Young saplings of both species were able to grow rapidly even at moderately low light, e.g., $10 \mathrm{~mol} \mathrm{~m}^{-2} \mathrm{~d}^{-1}$ or $16 \%$ of full sun (PFS). Older $P$. ponderosa saplings appeared to require $>20$ 
mol m $\mathrm{m}^{-2}$ of light to keep from stagnating, which was not true for the more shade-tolerant $C$. decurrens.

For $P$. jeffreyi, the shape of the graph of growth plotted against light (Fig. 2) suggests that at light levels $>25 \mathrm{~mol} \mathrm{~m}^{-2}$ $\mathrm{d}^{-1}(40 \%$ of full sun; PFS), growth is essentially linear. There is a long left-hand tail consisting of individuals persisting at low light with very low growth rates, and it is the transition between flat and linearly increasing growth that makes the exponential equation the best model. Our results suggest that, consistent with classification as an extreme shadeintolerant [46], saplings of $P$. jeffreyi continue to increase in radial growth rate at high light levels.

Our data suggest that as a rule of thumb, average growing season light levels exceeding $25 \mathrm{~mol} \mathrm{~m}^{-2} \mathrm{~d}^{-1}$ (40 PFS) would be required to sustain rapid growth of saplings of the most shade-intolerant conifer species of Sierran mixed-conifer forest. The lack of detectable light-dependent radial growth of $A$. concolor, P. menziesii, and P. lambertiana) suggests that growth will not accelerate greatly with large increases in light, but any such inference is limited because few individuals were found growing in high-light conditions. We further caution that these conclusions are based on a small dataset from a restricted geographic area, and we expect that the growth parameters extracted from the data will be updated in the future as more studies are done.

Direct measurements of light availability are impractical for forest managers to obtain, but canopy cover (i.e. the proportion of forest floor covered by the vertical projection of tree crowns)[47] is a widely used metric that may be a useful surrogate. We combined data from studies of fuels treatments in mixed-conifer forest in the central Sierra (Blodgett Forest) [48, 49] and southern Sierra (Teakettle Experimental Forest) $[5,50]$ to investigate the relationship between stand-level canopy cover and mean understory light. Canopy closure data (sensu Jennings et al. [47]) of North et al. [5] were converted to canopy cover using the approach of Fiala et al. [51]. At any given canopy cover, light in the southern Sierra forest was $\sim 20$ PFS greater than that in the central Sierra forest, but in both forests a $0.1 \mathrm{~m} / \mathrm{m}^{2}$ increase in canopy cover corresponded with a 7-8 PFS decrease in understory light (Fig. 3). The relatively dark understory of the central Sierra forest was probably due to a more vertically even canopy, higher stem densities, and fewer gaps than in the southern Sierra forest $[48,52]$. Our study suggests that even after vigorous fuels treatments in the central Sierran stands there would be insufficient light to support rapid growth of shade intolerants, but that most fuels treatments in the southern Sierran stands would increase mean light levels to levels adequate to support rapid growth of intolerants. We caution, however, that our study took place in the northern Sierra Nevada, and there may be ecotype differentiation within conspecific conifers in southern and northern Sierra Nevada.

It is unclear whether a large proportion of ground area in the pre-European-settlement forests of the Sierra Nevada might have had high enough irradiance to support rapid growth of shade-intolerants. Most studies which have reconstructed historic Sierran mixed-conifer forest suggest stands were characterized by clumped tree distributions interspersed with high-light open gaps [3, 5, 53]. Application of spatially explicit light models [54] to these historic stand reconstructions would help reveal whether forests thinned by an active fire regime had high-light understory conditions favored by shade-intolerant species.

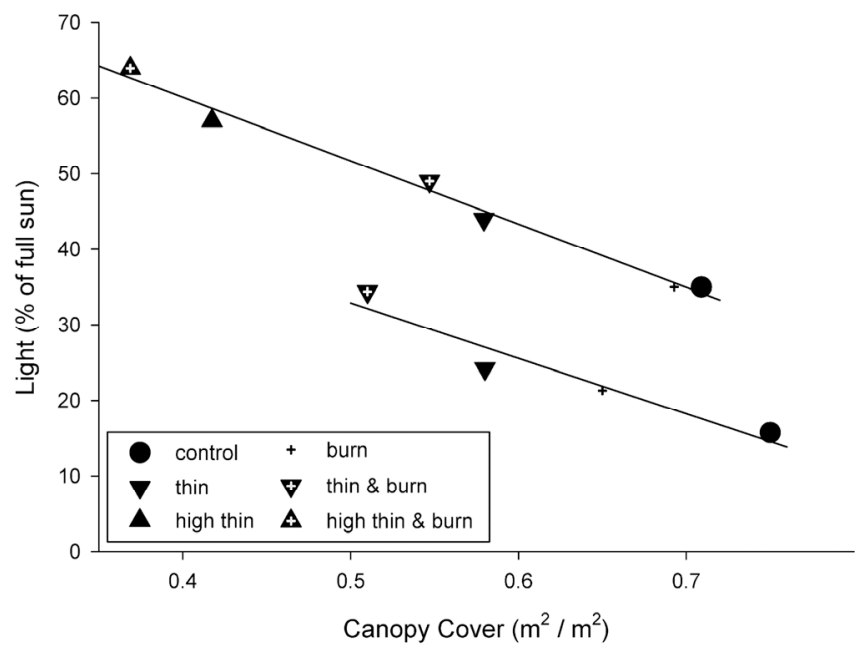

Fig. (3). Mean understory light with respect to canopy cover in Sierran mixed-conifer forest after experimental fuels-reduction treatments at Teakettle Experimental Forest (North et al. 2007, Zald et al. 2008) and Blodgett Forest (Stephens and Moghaddas 2005, Moghaddas et al. 2008).

\section{Water Limitation and the Carbon Isotope Ratio}

Our second hypothesis, that variation in water status explains more of the growth of shade-tolerant than intolerant species, was not supported by the data. Despite the lengthy summer drought we saw no evidence for water limitation in any species. Our measurements of water availability in the environment were rudimentary; the samples taken at the base of each plant encompassed just a small portion of the belowground resource environment, and sampling at the beginning and end of the growing season simplified within-season water dynamics and ignored year-to-year changes in water availability. Nevertheless, the $\delta^{13} \mathrm{C}$ analyses of stem wood were consistent with the absence of water limitation for most species, showing higher $\delta^{13} \mathrm{C}$ in faster-growing individuals of all species except $P$. lambertiana. For the three most shadetolerant species, this pattern may have been related to direct and indirect effects of elevation. Elevation was positively related to growth rate for these species (Table 2), perhaps because cooler temperatures may have ameliorated inhibition of photosynthesis. Faster-growing plants have increased demand for $\mathrm{CO}_{2}$, leading to lower discrimination against ${ }^{13} \mathrm{CO}_{2}$ and elevated ${ }^{13} \mathrm{C}$. The resulting positive correlation between elevation and $\delta^{13} \mathrm{C}$ would be enhanced by intrinsically lower discrimination against ${ }^{13} \mathrm{C}$ at higher elevations [37].

Our results indicate that it may be legitimate to ignore growth response to soil moisture in simulation modeling of resource-dependent Sierran lower montane conifer growth, at least at the latitude at which our study took place. Water is likely to become more limiting at more southerly latitudes in the north-south oriented Sierra Nevada range [50,52]. 


\section{Size and Age Effects on Resource-Dependent Growth}

Sapling growth rate is often analyzed as a relative growth rate (RGR), partly because this metric may compensate for differences in growth due to differing plant sizes at the beginning of a study. Nevertheless, RGR has several potential disadvantages as a response variable: it declines as plants grow larger [55] and it can distort the interpretation of growth-resource relationships at small and large plant sizes. Using absolute radial growth as the dependent variable and estimating a parameter describing the scaling relationship between size (in our case, stem diameter) and growth can circumvent these issues [26]. We followed this procedure, estimating scaling parameters between 0.61 and 0.71 for three species (Table 4), compared to scaling parameters of 0.7 to 0.97 for four northern hardwood tree species [26]. Because the size-scaling parameters $(c)$ estimated were $<1$, using RGR as a response variable (equivalent to $c=1$ ) would have created a size-bias. Estimation of a size-scaling parameter was justified, but given our small sample sizes the additional parameter to be estimated limited our ability to detect limitations from multiple resources.

Age and size are generally correlated in perennial plants because plants grow larger as they age. We expected both size and age to be good predictors of absolute radial growth rate, but this expectation was not met: species' radial increment growth was predicted by age or stem diameter but not both (Table 3). Age was a better growth-scaling factor than size for $P$. ponderosa, $C$. decurrens, and $P$. lambertiana. Young trees of the three species were growing faster than older ones, as indicated by the negative values of the age-scaling parameters (Table 4). This finding may have been partly an artifact of our sampling protocol, which constrained sapling selection by height (between 0.5 and 2 $\mathrm{m})$ but not age. Older trees remaining in this size class would tend to be those that grew slowly. Thus, estimating this scaling parameter was an effective way of allowing a resource-dependence signal to be extracted, particularly for $P$. ponderosa, but probably did not reveal ontogenetic changes in growth rate.

\section{CONCLUSIONS}

We found strongly light-dependent growth in naturally established individuals of the intolerant pine species $P$. jeffreyi and $P$. ponderosa, and moderately strong lightdependent growth in $C$. decurrens, Including sapling age or size (stem diameter) in growth models was necessary for accurate interpretation of growth-resource relationships for each species. No resource dependencies of $A$. concolor, $P$. menziesii and $P$. lambertiana growth were discovered. Our work may suggest a minimum light threshold to trigger rapid growth of the shade-intolerant species $P$. jeffreyi. Posttreatment data from other studies in Sierran mixed-conifer forest suggest that understory light is linearly related to vertically projected canopy cover. The rate of change of understory light with respect to canopy cover is comparable between forests but the absolute amount of light is strongly related to local forest structure. These findings contribute to assessment of circumstances under which fuels treatments in Sierra Nevada mixed-conifer forest will contribute to regeneration of shade-intolerant species and restoration of historic species composition.

\section{ACKNOWLEDGEMENTS}

We thank C. Salk for contributions to field and lab components of the study. Timothy Doane provided laboratory expertise; H. Lau, B. Rock, and J. Katz assisted with field work. C. Millar provided the use of her dendroecology lab and D. Delany provided training. Lora Murphy and C. Canham provided computer code in R. A reviewer suggested incorporation of scaling factors into the null models. The personnel of the Supervisor's Office of the Plumas National Forest and the Mount Hough Ranger District facilitated this work. This work was supported by the Joint Fire Sciences Program and United States Department of Agriculture Forest Service, Region 5.

\section{REFERENCES}

[1] McKelvey KS, Johnston JD. Historical perspectives on forests of the Sierra Nevada and the Transverse Ranges of southern California: forest conditions at the turn of the century. In: Verner J, McKelvey KS, Noon BR, Gutiérrez RJ, Gould GI, Beck TW, Eds. The California Spotted Owl: A Technical Assessment of Its Current Status. Albany, California, USDA Forest Service, Pacific Southwest Research Station. General Technical Report PSW-GTR133; 1992.

[2] Taylor AH. Fire regimes and forest changes in mid and upper montane forests of the southern Cascades. J Biogeogr 2000; 27: 87104.

[3] Taylor AH. Identifying forest reference conditions on early cutover lands, Lake Tahoe basin, USA. Ecol Appl 2004; 14: 1903-20.

[4] Beaty RM, Taylor AH. Fire disturbance and forest structure in oldgrowth mixed conifer forests in the northern Sierra Nevada, California. J Veg Sci 2007; 18: 879-90.

[5] North M, Innes J, Zald H. Comparison of thinning and prescribed fire restoration treatments to Sierran mixed-conifer historic conditions. Can J Forest Res 2007; 37: 331-42.

[6] Ansley JAS, Battles JJ. Forest composition, structure, and change in an old-growth mixed conifer forest in the northern Sierra Nevada. J Torrey Bot Soc 1998; 125: 297-308.

[7] North MP, Hurteau M, Fiegener R, Barbour MG. Influence of fire and El Nino on tree recruitment varies by species in Sierran mixed conifer. Forest Sci 2005; 51: 187-97.

[8] Blackwell J, Troyer JD. Record of Decision: Sierra Nevada Forest Plan Amendment Final Supplemental Environmental Impact Statement. Vallejo, California, Pacific Southwest Region. USDA Forest Service Management Bulletin R5-MB-046; 2004. Available from http://www.fs.fed.us/r5/snfpa/final-seis/

[9] York RA, Battles JJ, Heald RC. Edge effects in mixed conifer group selection openings: tree height response to resource gradients. For Ecol Manag 2003; 179: 107-21.

[10] Westerling AL, Hidalgo HG, Cayan DR, Swetnam TW. Warming and earlier spring increase western U.S. forest fire activity. Science 2006; 313: 940-2.

[11] Urban DL, Miller C, Halpin PN, Stephenson NL. Forest gradient response in Sierran landscapes: the physical template. Landscape Ecol 2000; 15: 603-20.

[12] Kercher JR, Axelrod MC. A process model of fire ecology and succession in mixed-conifer forest. Ecology 1984; 65: 1725-42.

[13] Baker FS. A revised tolerance table. J Forest 1949; 47: 179-81.

[14] Minore D. Comparative autecological characteristics of Northwestern tree species: a literature review. Portland, Oregon, USDA Forest Service, Pacific Northwest Forest and Range Experiment Station. General Technical Report PNW-GTR-87; 1979.

[15] Oliver WW, Dolph KL. Mixed-conifer seedling growth varies in response to overstory release. Forest Ecol Manag 1992; 48: 179-83.

[16] Pacala SW, Canham CD, Silander JA, Kobe RK. Sapling growth as a function of resources in a north temperate forest. Can J For Res 1994; 24: 2172-83.

[17] Martinez-Vilalta J, Sala A, Pinol J. The hydraulic architecture of Pinaceae - a review. Plant Ecol 2004; 171: 3-13.

[18] Urban DL. Modeling ecological processes across scales. Ecology 2005; 86: 1996-2006. 
[19] Powers RF. Mineralizable soil nitrogen as an index of nitrogen availability to forest trees. Soil Sci Soc Am J 1980; 44: 1314-20.

[20] Powers RF, Reynolds PE. Ten-year responses of ponderosa pine plantations to repeated vegetation and nutrient control along an environmental gradient. Can J Forest Res 1999; 29: 1027-38.

[21] Mencuccini M, Martínez-Vilalta J, Vanderklein D, et al. Sizemediated ageing reduces vigour in trees. Ecol Lett 2005; 8: 118390.

[22] Fowells HA, Schubert GH. Silvics of Sugar Pine. Berkeley, California, USDA Forest Service, Pacific Southwest Research Station. Technical Paper PSW-TP-14; 1956.

[23] York RA, Heald RC, Battles JJ, York JD. Group selection management in conifer forests: relationships between opening size and tree growth. Can J Forest Res 2004; 34: 630-41.

[24] Oliver WW, Ryker RA. Ponderosa pine. In: Burns RA, Honkala BH, Eds. Silvics of North America. Washington, DC, USDA Forest Service 1990. Available from http://www.na.fs.fed.us/spfo/pubs/ silvics manual/Volume 1/pinus/ponderosa.htm

[25] Kneeshaw DD, Kobe $\bar{R}$, Coates KD, Messier C. Sapling size influences shade tolerance ranking among southern boreal tree species. J Ecol 2006; 94: 471-80.

[26] MacFarlane D, Kobe RK. Selecting models for capturing tree-size effects on growth-resource relationships. Can J Forest Res 2006; 36: 1695-704.

[27] PRISM Group. PRISM climate chart. Oregon State University; 2006. Available from http://www.prismclimate.org

[28] Western Regional Climate Center; Available from http://www.wrcc.dri.edu

[29] Kurpius MR, Panek JA, Nikolov NT, et al. Partitioning of water flux in a Sierra Nevada ponderosa pine plantation. Agric For Meteorol 2003; 117: 173-92.

[30] McCune B, Grace JB. Analysis of Ecological Communities. Glenenden Beach, Oregon: MjM Software Design 2002.

[31] Forster JC. Soil nitrogen. In: Alef K, Nannipieri P, Eds. Methods in Applied Soil Microbiology and Biochemistry. San Diego: Academic Press 1995; pp. 79-87.

[32] Frazer GW, Canham CD, Lertzman KP. Gap Light Analyzer (GLA), Version 2.0. Bull Ecol Soc Am 2000; 81: 191-7.

[33] Monteith JB, Unsworth MH. Principles of Environmental Physics. $2^{\text {nd }}$ ed. London: Edward Arnold 1990.

[34] Howell TA, Meek DW, Hatfield JL. Relationship of photosynthetically active radiation to shortwave radiation in the San Joaquin Valley. Agric Meteorol 1983; 28: 157-75.

[35] Fowells HA. The period of seasonal growth of ponderosa pine and associated species. J Forest 1941; 39: 601-8.

[36] Brendel O, Iannetta PPM, Stewart D. A rapid and simple method to isolate pure alpha-cellulose. Phytochem Anal 2000; 11: 7-10.

[37] Warren CR, McGrath JF, Adams MA. Water availability and carbon isotope discrimination in conifers. Oecologia 2001; 127: 476-86.

[38] Stephenson NL. Climatic control of vegetation distribution: the role of the water balance. Am Nat 1990; 135: 649-70.
[39] SAS Institute. SAS OnlineDoc ${ }^{\circledR}$, Version 8. Cary NC: SAS Institute, Inc 1999.

[40] Kobe RK. Sapling growth as a function of light and landscape-level variation in soil water and foliar nitrogen in northern Michigan. Oecologia 2006; 147: 119-33

[41] Sit V, Poulin-Costello M. Catalog of Curves for Curve Fitting: British Columbia Ministry of Forests: Research Program 1994.

[42] R Development Core Team. R: A Language and Environment for Statistical Computing. Vienna, Austria: R Foundation for Statistical Computing 2008.

[43] Burnham KP, Anderson DR. Model Selection and Multimodel Inference: A Practical Information-Theoretic Approach. New York: Springer 2002.

[44] Hilborn R, Mangel M. The Ecological Detective: Confronting Models with Data. Princeton, New Jersey: Princeton University Press 1997.

[45] Lieffers VJ, Messier C, Stadt KJ, et al. Predicting and managing light in the understory of boreal forests. Can J Forest Res 1999; 29: 796-811

[46] Jenkinson JL. Jeffrey Pine. In: Burns RM, Honkala BH, Eds Silvics of North America. Washington DC, USDA Forest Service 1990. Available from http://www.na.fs.fed.us/spfo/pubs/silvics manual/Volume 1/pinus/jeffreyi.htm

[47] Jennings SB, Brown ND, Sheil D. Assessing forest canopies and understorey illumination: canopy closure, canopy cover and other measures. Forestry 1999; 72: 59-73.

[48] Stephens SL, Moghaddas JJ. Experimental fuel treatment impacts on forest structure, potential fire behavior, and predicted tree mortality in a California mixed conifer forest. Forest Ecol Manage 2005; 215: 21-36.

[49] Moghaddas JJ, York RA, Stephens SL. Initial response of conifer and California black oak seedlings following fuel reduction activities in a Sierra Nevada mixed conifer forest. Forest Ecol Manage 2008; 255: 3141-3150.

[50] Zald HSJ, Gray AN, North M, Kern RA. Initial tree regeneration responses to fire and thinning treatments in a Sierra Nevada mixedconifer forest, USA. Forest Ecol Manage 2008; 256: 168-79.

[51] Fiala AC, Garman SL, Gray AN. Comparison of five canopy cover estimation techniques in the western Oregon Cascades. Forest Ecol Manage 2006; 232: 188-97.

[52] Gray AN, Zald HS, Kern RA, North M. Stand conditions associated with tree regeneration in Sierran mixed-conifer forests. Forest Sci 2005; 51: 198-210.

[53] Bonnicksen TM, Stone EC. Reconstruction of a presettlement giant sequoia-mixed conifer forest community using the aggregation approach. Ecology 1982; 63: 1134-48.

[54] Gersonde R, Battles JJ, O'Hara KL. Characterizing the light environment in Sierra Nevada mixed-conifer forests using a spatially explicit light model. Can J Forest Res 2004; 34: 1332-42.

[55] Mencuccini M, Martinez-Vilalta J, Hamid HA, et al. Evidence for age- and size-mediated controls of tree growth from grafting studies. Tree Physiol 2007; 27: 463-73. 